\title{
The Effect of Mindfulness Therapy on Tolerance of Uncertainty and Thought- Action Fusion in Patients with Obsessive-Compulsive Disorder
}

\author{
Moslem Asli Azad ${ }^{1}$, Gholamreza Manshaei ${ }^{* 2}$, Amir Ghamarani ${ }^{3}$ \\ 1. Ph.D. Student of Psychology, Faculty of Psychology and Educational Sciences, Isfahan (Khorasgan) Branch, Islamic Azad \\ University, Isfahan, Iran \\ 2. Associate Professor, Department of Psychology, Faculty of Psychology and Educational Sciences, Isfahan (Khorasgan) Branch, \\ Islamic Azad University, Isfahan, Iran \\ 3. Assistant Professor, Department of Psychology and Education of Children with Special Needs, Isfahan University, Iran
}

Received: April 18, 2018

Accepted: July 3, 2018

\begin{abstract}
Background and Purpose: Obsessive-compulsive disorder is a serious disorder that affects psychological, communicative, social, and emotional processes. Accordingly, the present study was conducted with the aim of investigating the effect of mindfulness therapy on tolerance of uncertainty, and thought-action fusion in patients with obsessive-compulsive disorder.

Method: This was a semi-experimental study with pre-test-post-test control group design with a follow-up of two months. The sample consisted of 30 patients with obsessive-compulsive disorder in Isfahan during the academic year of 2017-2018. They were selected by purposeful sampling. The experimental group received mindfulness intervention in 10 sessions of 75 minutes during three months. Maudsley obsession questionnaire (Hajson and Rachman, 1980), tolerance of uncertainty (Mcleen, 1993), and thought-action fusion questionnaire (Shefran et.al, 1996) were used to collect data. Data were analyzed by repeated measure ANOVA.

Results: The results showed that mindfulness therapy had a significant effect on the tolerance of uncertainty and thought-action fusion in patients with obsessive-compulsive disorder ( $\mathrm{F}=11.13$, $\mathrm{F}=79.98, \mathrm{P}<0.001)$. Also, the effect of this treatment is maintained during the follow-up phase $(\mathrm{P}<0 / 001)$. The degree of statistical effect of mindfulness therapy on tolerance of uncertainty and thought-action fusion were $40 \%$ and $73 \%$ respectively.

Conclusion: Based on the findings of the present study, it can be concluded that by creating knowledge of thoughts and feelings, the mindfulness therapy can increase tolerance of uncertainty and reduce the thought-action fusion in patients with obsessive compulsive disorder.

Keywords: Mindfulness, tolerance of uncertainty, thought-action fusion, obsessive-compulsive disorder
\end{abstract}

Citation: Asli Azad M, Manshaei G, Ghamarani A. The effect of mindfulness therapy on tolerance of uncertainty and thought-action fusion in patients with obsessive-compulsive disorder. Quarterly Journal of Child Mental Health. 2019; 6(1): 83-94.

*Corresponding author: Gholamreza Manshaei, Assistant Professor, Department of Psychology, Hamedan Branch, Islamic Azad University, Hamedan, Iran.

Email: Smanshaee@yahoo.com Tel: (+98) 9133170300 


\section{تأثير درمان ذهن آكاهى بر تحمل ابهام و در آميختكى فكر و عمل مبتلايان به اختلال وسواس بى اختيارى}

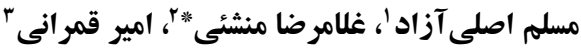

ا. دانشجوى دكتراى روانشناسى عمومى، دانشكده روانشناسى و علوم تربيتى، واحد اصفهان (خوراسگان)، دانشخاه آزاد اسلامى، اصفهان، ايران

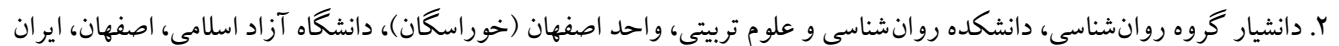

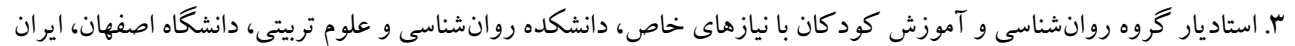

تاريخ يذيرش:F/Ir/F

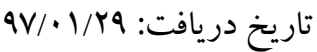

جكيده

زمينه و هدف: وسـواس بىاختيارى، اختلالى جدى اسـت كه ديخر فر ايندهاى روانشـناختى، ارتباطى، اجتماعى، و هيجانى فرد را با آسيب مواجه مى كند. بر همين اساس يثوهش حاضر با هدف بررسى تأثير درمان ذهن آكاهى بر تحمل ابهام و در آميختكى فكر و عمل

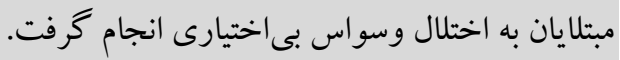

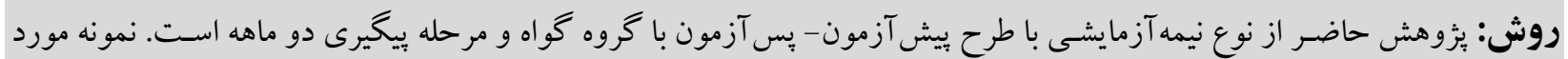

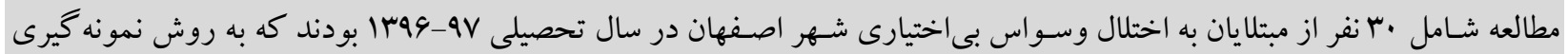

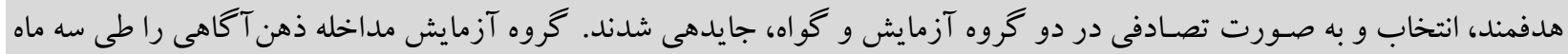

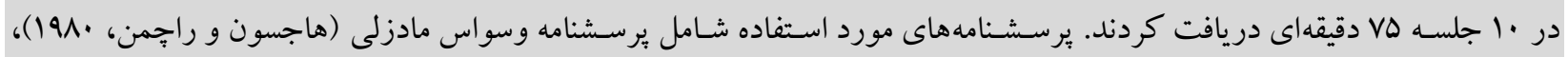

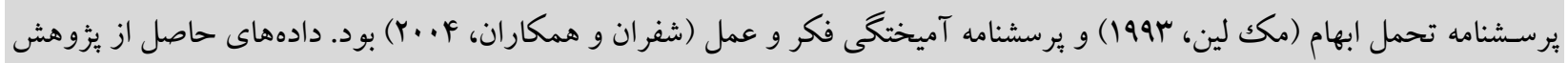

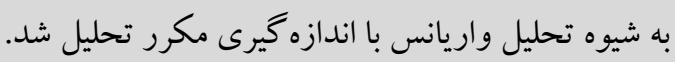
يافتها: نتايج نشـان داد كه درمان ذهن آكًاهى بر تحمل ابهام و در آميختخى فكر و عمل مبتلايان به اختلال وســـواس بـى اختيارى تأثير

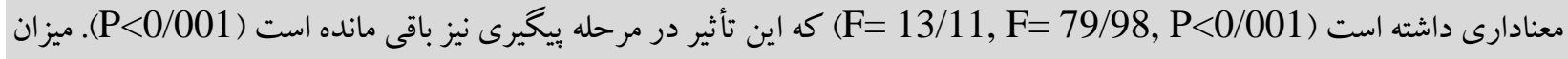

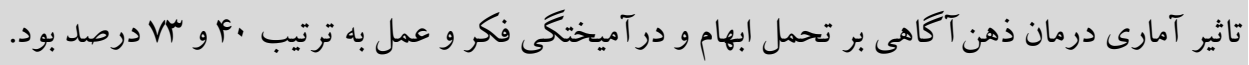

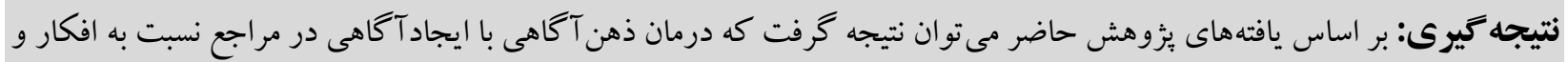

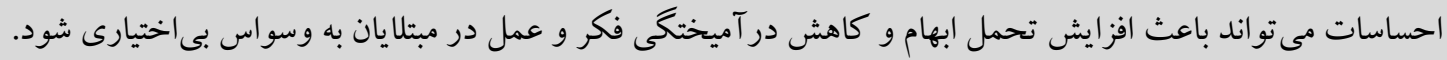
كليدوازهها: ذهن آكاهى، تحمل ابهام، در آميختخى فكر و عمل، اختلال وسواس فكرى-عملى

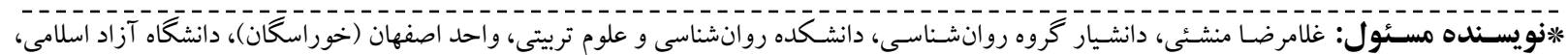


عدم تحمل ابهامَّ ديخر مؤلفهاى اســت كه در بديدايى و

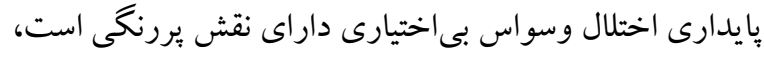

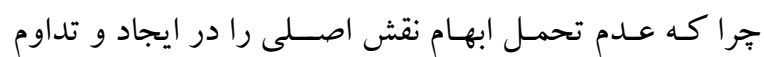

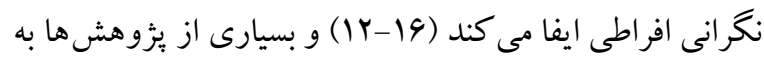
بررسى نقش تحمل ابهام در اين اختلال يُرداختهاند (IV). كرون

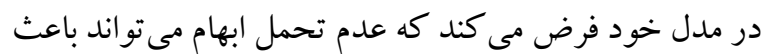

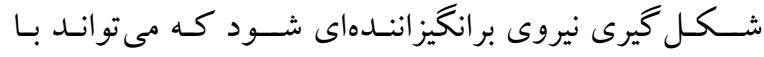

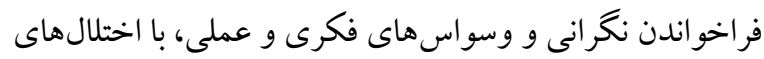

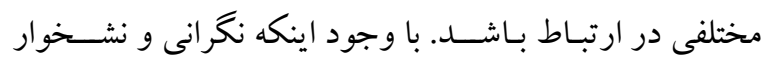

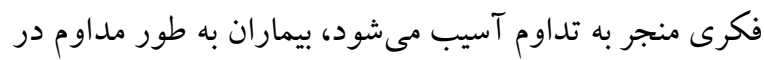

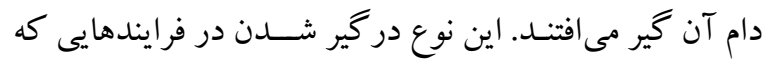
زيانهايى نيز براى بيمار ان دارد، به دليل فوايدى اسـت كه اين

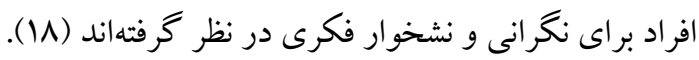

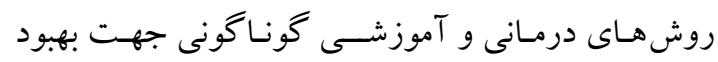
مؤلفههاى روانشــناختى، هيجانى، عاطفى، و ارتباطى كود كان و نوجو انان مبتلا به اختلال وسواس بى اختيارى به كار كر فته شده

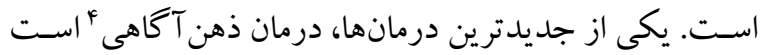

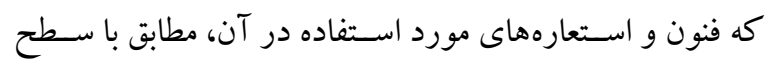
شـناختى كود كان و نوجوانان طراحى شــده و در يزوهشهاى

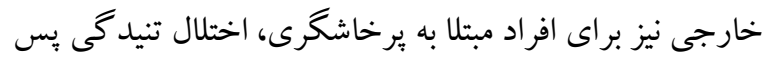

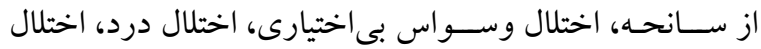
افسـردگى و نظاير آن به كار رفته اسـت (19). همجِنين درمان

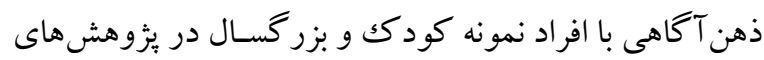

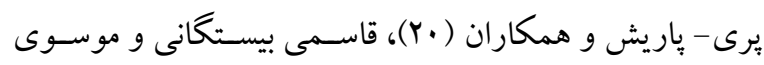

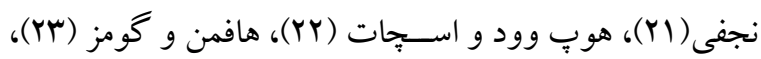
كروسـول و همكاران (YF)، و كروسكا و همكاران (YD) مورد

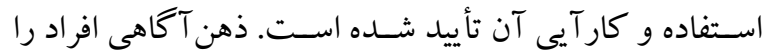
توانمند مى سازد كه بتوانند افكار و رفتارهايى كه قبلاً ناهشيار يا

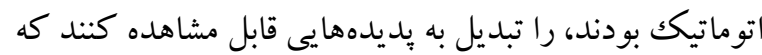

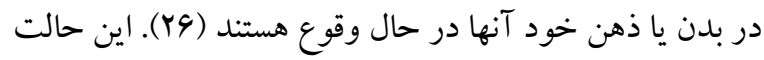

3. Intolerance of uncertainty 4. Mindfulness Therapy

\section{مقدمه}

وسـواس بى اختيارى '، اختلال اضطر ابى بيجيجلده، تضعيف كنتده و مزمن است كه ب-r درصد كود كان و بزر گسالان به آن مبتلا هستند ( ا و Y). اين اختلال مشكلى جدى در زمينه سلامت روان محسوب مىشود كه شروع آن حداقل در نيمى از مراجعان در دوران كودكى و نوجوانى اسـت (r). مشـخصه اصلى وسواس بى اختيارى، افكار و يا اعمال وسـواسـى تكرارشـونده اسـت. شـدت اين افكار و اعمال وسـواسى به اندازهاى است كه براى بيمار بسـيار وقت گير (بيش از يكك سـاعت در روز) و منجر به يريشـانى يا آسـيب قابل ملاحظه مىشـوند (F). شواهدى و جود دارد كه نشـان مىدهد نو جوانان به طور كلى افكار مزاحمى را تجربـه مى كنتـد كـه متفـاوت از افكار تجربه شـــده در اختلال وسـواس بـى اختيارى نيسـتند و اكر اين افكار منجر به ناراحتى شــده و يا به شــــه فعال تر مديريت شــوند معمولا براى مدت طولانى ترى تداوم مى يابند (ه). اختلال وسواس به دليل خاصيت نـاتوان كننـد گى مى توانـد حيطههاى مختلف تحول كود كان و نوجوانان را متأثر ساخته و از اين طريق عملكرد كلى آنان را با آسيب جدى مواجه سازد (9). يثزوهش هـاى كونـاكون نشــان داده اند كه بين وســـواس بى اختيـارى و آميختكى فكر و عمـل ' رابطهـ معنـادار و قوى وجود دارد (V-9). آميختخى فكر - عمل به عقايدى اشاره دارد كـه در آن افكار و اعمال به طور غيرقابل تفكيكى به يكديگر ييوسـته و متصـل اند ( •() و دو شـكل خاص دارد: () احتمال آميختخى: يعنى اعتقـاد بـه اينكـه افكار نـاخو اســته و مزاحم، مى توانند باعث وقوع حوادث خاصسى شوند و يا احتمال وقوع حوادث خـاصسىى را افزايش دهند، Y) اخلاق آميختكى فكر و عمل، يعنى اعتقاد به اين كه افكار غيرقابل يذيرش و مزاحم از لحاظ اخلاقى برابر و معادل با اعمال و رفتارهاى آشكار غيرقابل

$$
\text { يذيرش است (11- - (1). }
$$

1. Obsessive- Compulsive Disorder

2. Thought - Action Fusion 
ذهن آگَاهى بر در آميختكى فكر و عمل و تحمل ابهام مبتلايان به اختلال وسواس بى اختيارى تأثير دارد؟

روش

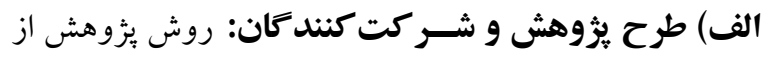

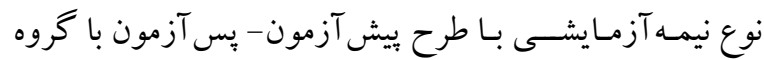

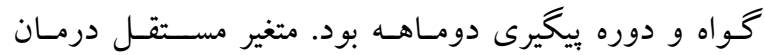

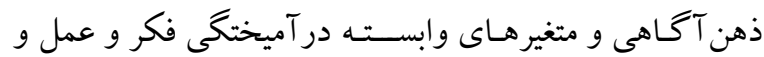

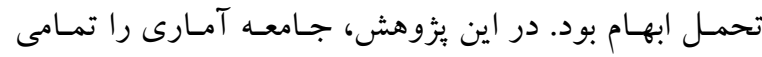

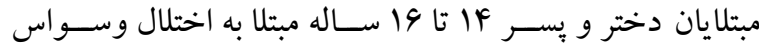
بى اختيارى مشـغول به تحصسيل در مدارس دوره متوسطه اول شـهر اصفنهان در سـال تحصسيلى جهت انتخاب نمونه از روش نمونه گيرى غير تصـادفى هدفمند

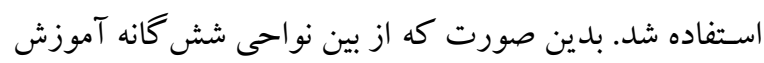
و برورش شهر اصفهان، ناحيه 9 انتخاب شـد. سبس به منظور شناسايى دانش آموزان داراى علائم اختلال وسواس بى اختيارى،

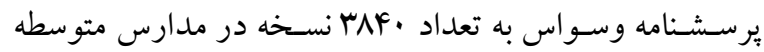

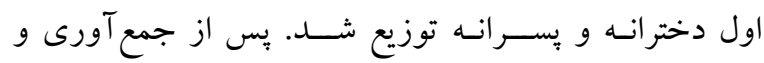

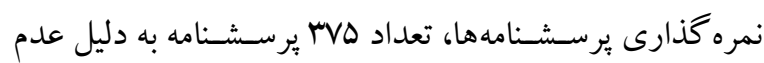

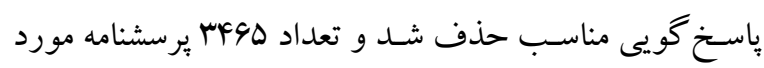
تحليل قرار گرفت. در كام بعد، دانش آموزانى كه نمرات بالاتر

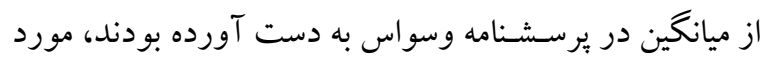

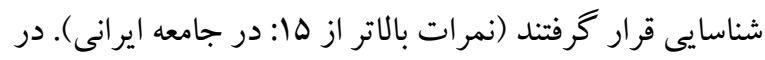

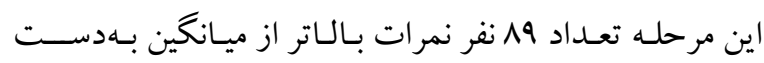

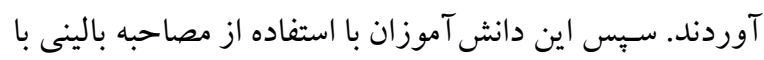

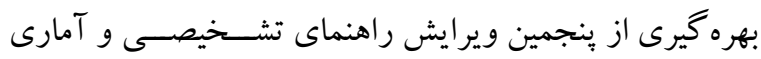
اختلالات روانى' توسط نويسنده اول مقاله (دانشجوى دكتراى

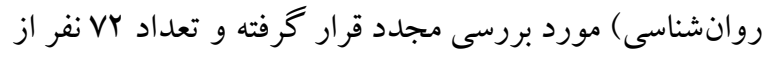

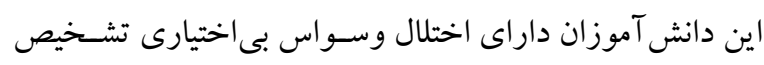

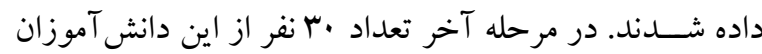

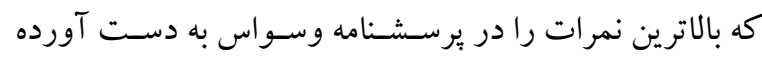

به عنوان ادراكك مجدد توصسيف شــده اسـت، يعنى آنجه قبلاً

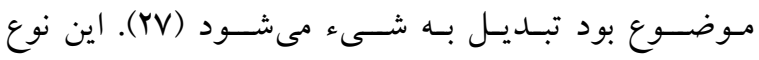

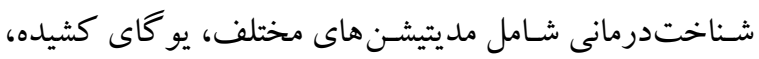

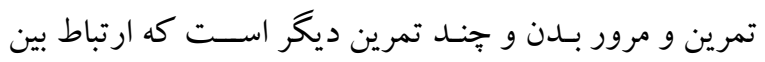

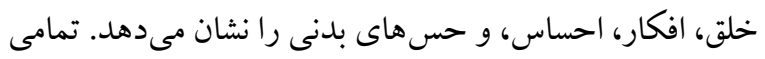
اين تمرينهـا بـه نوعى توجه به موقعيتهاى بدنى و وييرامون را در لحظه حاضــر ميســر مىســازند و يردازش هاى خود كار را

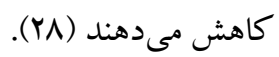
درباره ضـرورت انجام يزوهش حاضـر بايد اشاره كرد كه

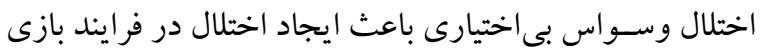

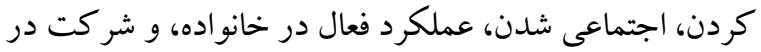
مدرسـه در نزد كود كان و نوجو انان مىشـود (جو). اختلال در عملكرد تحصـيلى نوجوانـان نيز مىتواند مشــكل در تمركز،

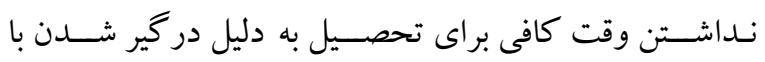

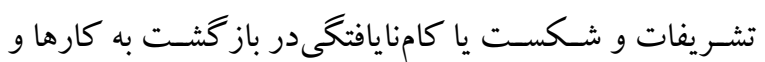
تكاليف مدرسه را در بى داشته باشد (·r). همجنين بايد اشاره

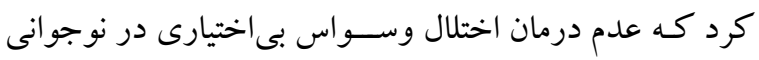

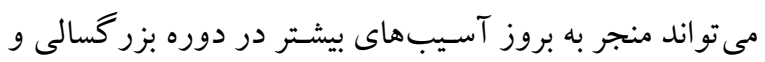

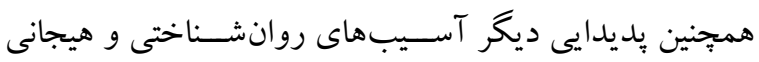

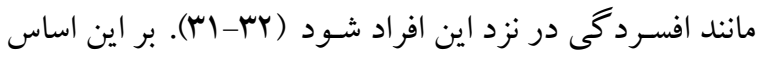

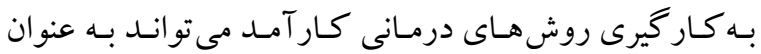

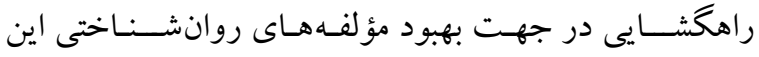

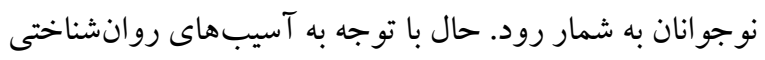
و هيجانى در نوجوانان مبتلا به اختلال وسواس بىاختيارى مانند

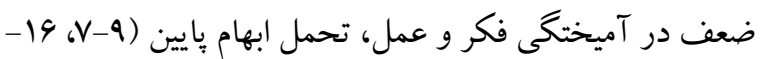

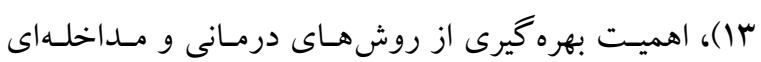
مناسـب، و از سـوى ديخر تأييد كار آيى درمان ذهن آكاهى در

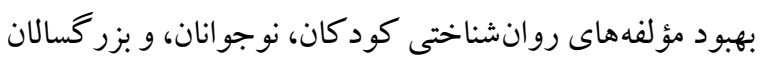

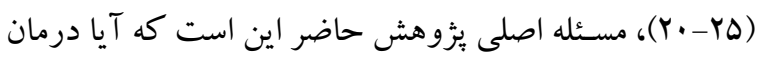

1. Diagnostic and statistical manual of mental disorders 5th edition (DSM- V) 


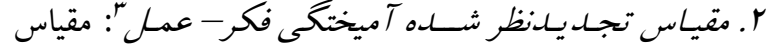

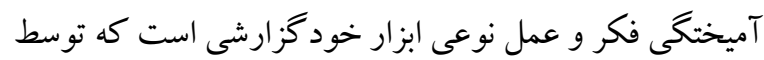

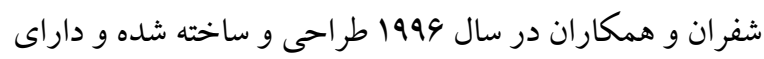

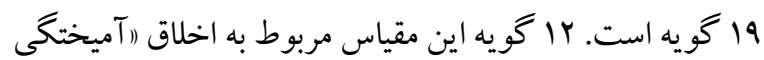

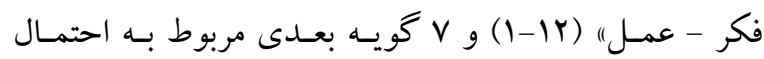

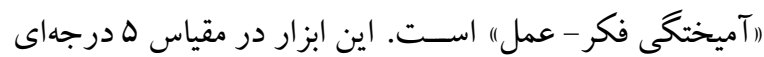

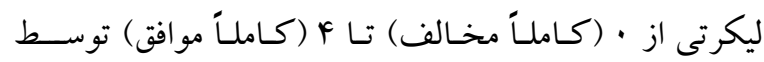

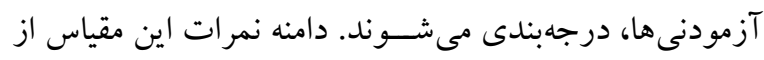

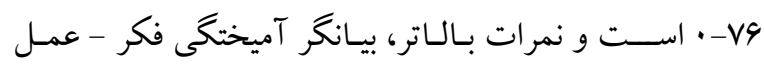
شـديدتر در فرد اسـت. شـفران و همكاران آلفاى كرونباخ اين

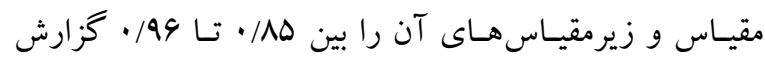

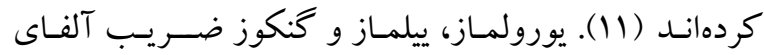
كرونـبـاخ احتمـال آميختخى فكر - عمـل را بو/. •، اخلـاق

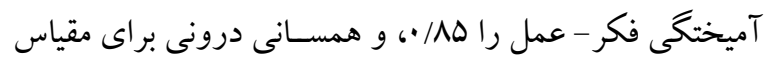

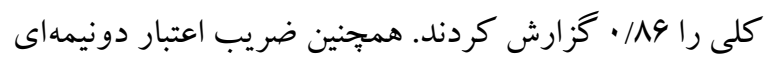

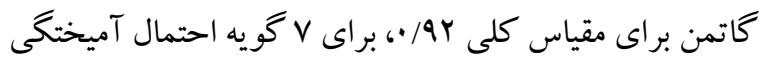

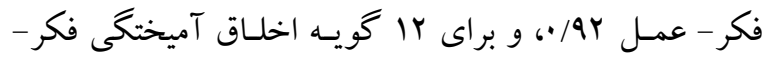

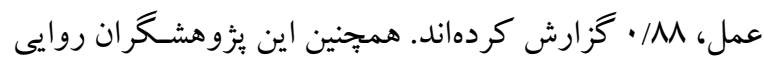

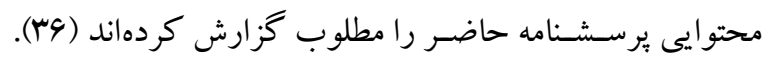
اعتبار برسشنامه حاضر در اين يُزوهش به وسيله ضريب آلفاى

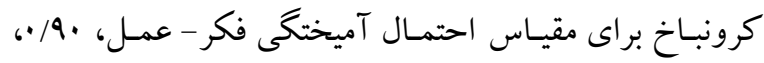

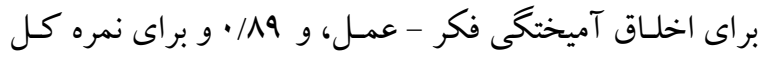
يرسنامه •9/9 • محاسبه شد.

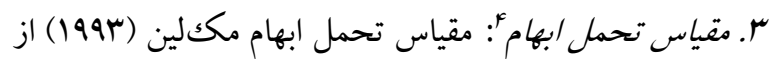

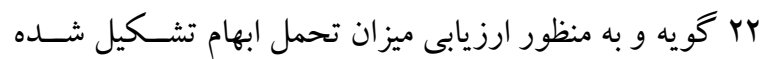
است. نسخه بعدى اين برسشنامه در rا سوال تدوين شده است كه در يثزوهش حاضسر نيز از اين فرم استفاده شده است. ياسخ

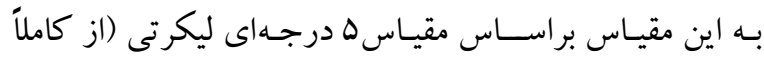

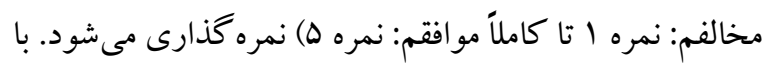

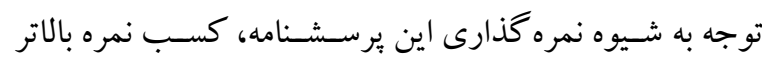

3 . Tolerance of uncertainty

4. Thought-action fusion questionnaire
بودند (نمرات بالاتر از ميانگين و به صورت ترتيبندى شده)، انتخاب و به صـورت تصــادفى در گروههاى آزمايش و گو اه

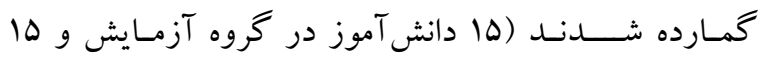

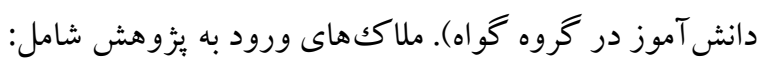
كسب نمره بالاتر از ميانگين در برسشنامه وسواس، داشتن علائم

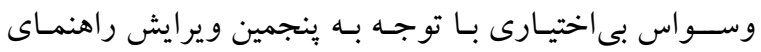

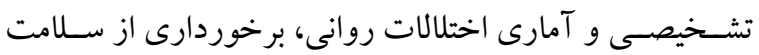
جسمى، تحصيل در دوره متوسطه اول، و داشتن سن سا تا 19 سـال بود. همجينين ملـاككهاى خروج از يثزوهش نيز شــامل: غيبت در دو جلســه آموزشـى و عدم همكارى، انجام ندادن تكاليف مشــخص شــده در دوره آموزشسى، و بروز حوادث بيشبينى نشده بود. ب) ب ابزار ا. بِرسشـنامه وسواس مادزلى ': /ين بِرسشنامه به منظور بررسى

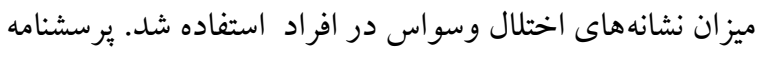
وسـواس توسط هاجسـون و راجمن بدر سـال •191 به منظور ئزوهش در مورد نوع و حيطه مشكلات وسواس تهيه شده است

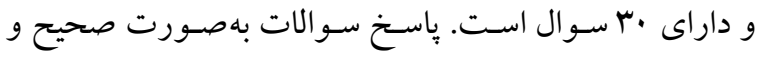

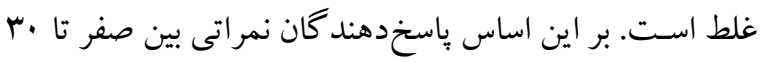

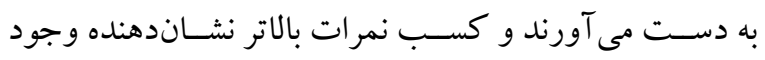
اختلال وسواس در افراد است. راجمن و هاجسون شاخصهاى

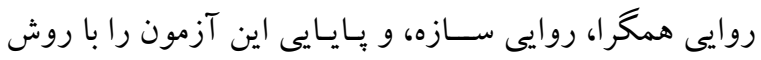

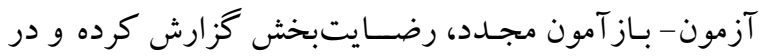
نمونههاى مبتلا به اختلال وســواس بى اختيارى و افر اد فاقد اين

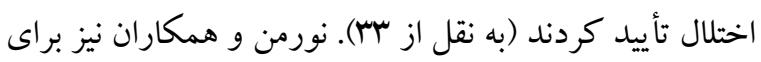

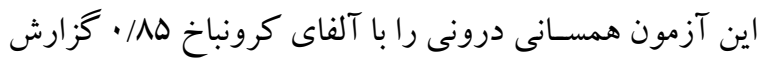
كردند (MF). در ايران نيز محمدخانى و فرجاد روايى محتوايى

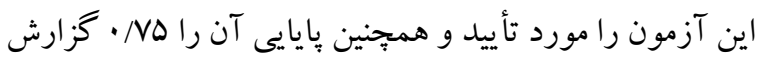

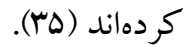

1. Maudsley obsession questionnaire 2. Rachman \& Hodgson 
ج) برنامه مداخلهاى: برنامه مداخلهاى اين مطالعه بركرفته از

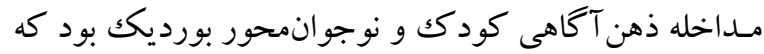
اعتبار آن توسط منشئى، اصلى آزاد، حسينى و طيبى (19) مورد

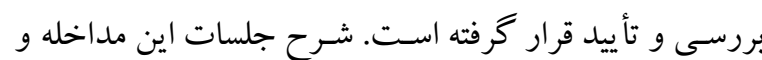
همجنين تمرينات و استعارههاى به كار رفته در آن مختص سن كودكى و نوجوانى اسـتـ اين جلســات در قالب · ا جلسـهـ

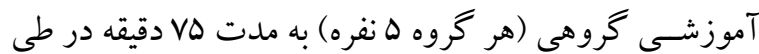

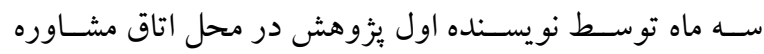

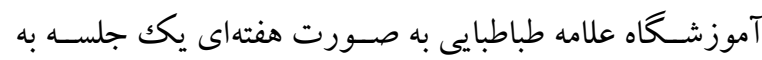

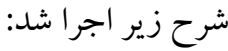

نشان دهنده تحمل ابهام بايين تر است و بالعكس. اين مقياس از همســانى درونى مناسـب (آلفاى كرونباخ = •9/ •) برخوردار

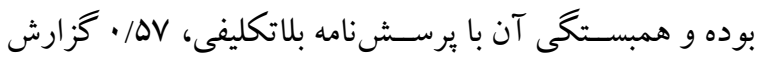

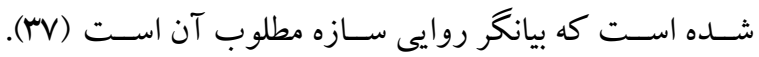

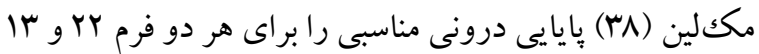

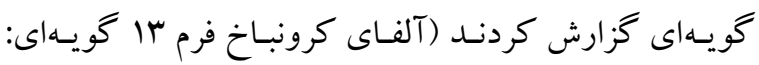

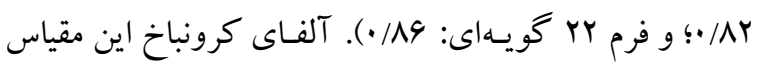

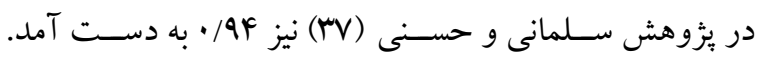
همجنين در مطالعه حاضـر، اعتبار برسـشــنامه حاضـر به وسـيله ضريب آلفاى كرونباخ M M • محاسبه شد.

جدول ا: خلاصه جلسات درمان ذهن آكاهى (19)

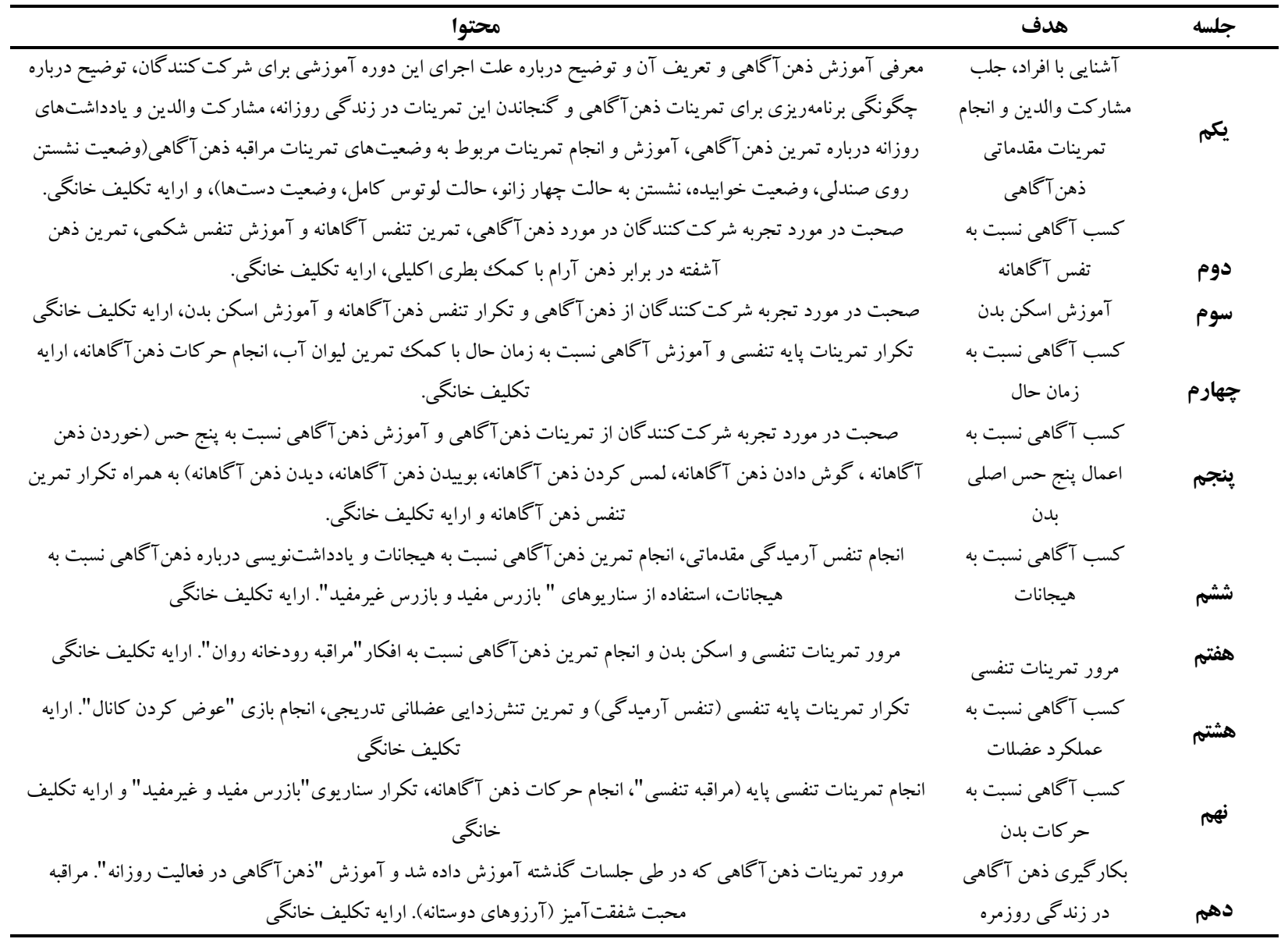

مر اجعه به مدارس متوســطه اول اين ناحيه، با كمكك ابزارهاى لـازم افراد نمونـه انتخـاب شـــند و به تصــادف درخروههاى
د) روش اجرا: جهت انجام يثزوهش ابتدا هماهنگى هاى لازم با

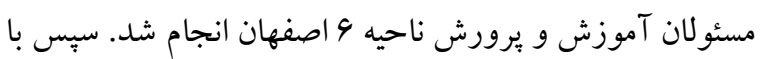


در اين بثزوهش براى تجزيـه و تحليـل دادههـا از تحليـل

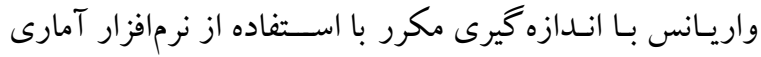

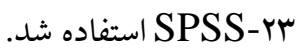

\section{يافتهها} نتـايج آمـار توصـيفى شــامـل ميانخين و انحر اف اســاندارد

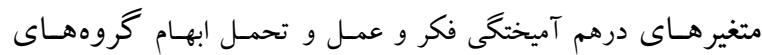
آزمايش و گو اه در جدول ب ارائه شده است.
آزمايش و گو اه جايدهى شــند. در نهايت، بر روى گروههاى

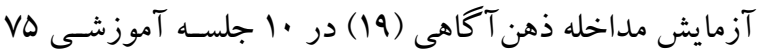

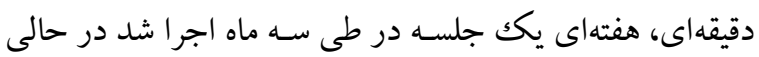

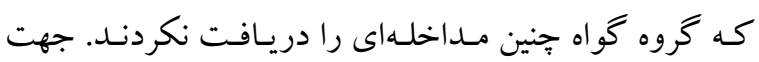

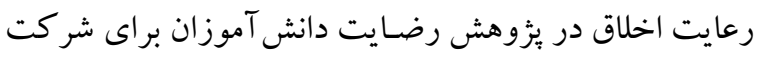
در برنـامـه مــاخله جلب شـــد و آنها از تمامى مر احل مداخله

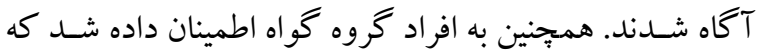

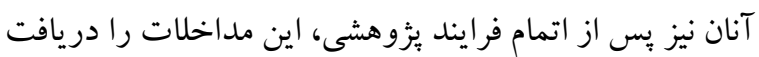

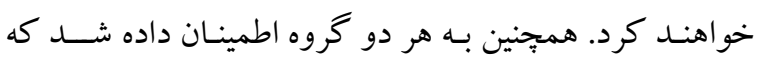
اطلاعات آنها محرمانه باقى مى ماند و نيازى به درج نام نيست.

جدول r: نتايج آمار توصيفى در مراحل ييش آزمون، يس آزمون، و ييكيرى

\begin{tabular}{|c|c|c|c|c|c|c|c|}
\hline \multicolumn{2}{|c|}{ بيغيرى } & \multicolumn{2}{|c|}{ هִ بس آزمون } & \multicolumn{2}{|c|}{ بيش آزمون } & \multirow{2}{*}{ كروهها } & \multirow{2}{*}{ مؤلفهها } \\
\hline انحر اف معيار & ميانكين & انحراف معيار & ميانكين & انحر اف معيار & ميانكين & & \\
\hline$\Delta / 9 \mu$ & $F \cdot / \Delta r$ & $\Delta / F q$ & $\mu q / r$. & $9 / 9 r$ & $\Delta r / \Delta r$ & كروه آزمايش & \\
\hline V/a1 & $\Delta r / .9$ & 9/9r & $\Delta r / \Lambda$. & G/NI & $\Delta r / r q$ & كروه كواه & \\
\hline $4 / 91$ & $r \cdot / 49$ & $\Delta / r q$ & $r r / a r$ & $\Delta / F F$ & Fi/ar & كروه آزمايش & \\
\hline $\mathrm{F} / \mathrm{gV}$ & $r q / 4$. & $F / \wedge q$ & $r \mid / 1$. & $F / N$. & Fi/rq & كروه گواه & \\
\hline
\end{tabular}

نتايج آن معنادار نبود كه اين يافته نشـان مىدهد كه بيشفرض

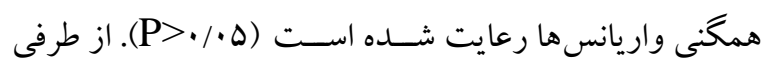

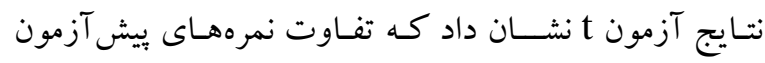

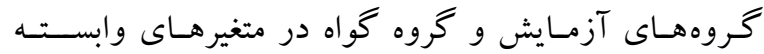

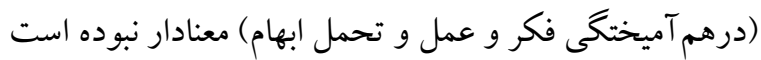

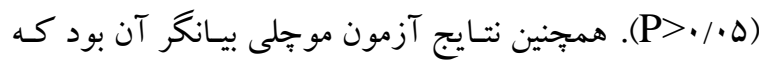

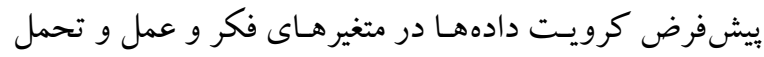

$$
\text { ابهام رعايت شده است (ه •/P> (P). }
$$

قبـل از ارائـه نتـايج تحليـل آزمون واريانس با اندازهگيرى

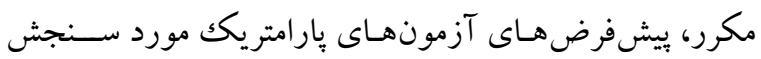

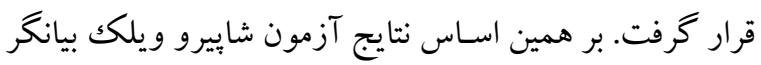
آن بود كـه بِيشفرض نرمـال بودن توزيع نمونسهاى دادهــا در

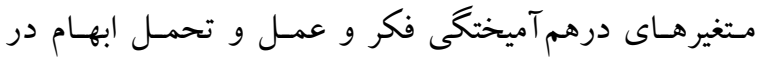

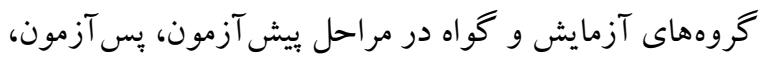

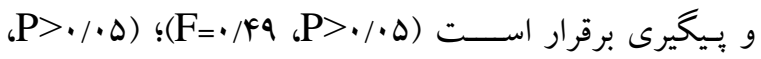
 واريانس نيز توسط آزمون لوين مورد سنجش قرار گرفت كه

جدول س: تحليل واريانس با اندازهكيرى مكرر جهت بررسى تاثير ات درون و بين تروهى براى مؤلفههاى درهم آميختكى فكر و عمل و تحمل ابهام

\begin{tabular}{|c|c|c|c|c|c|c|c|c|}
\hline توان & اثدازه & مقدار p & f مقدار & مجانغين & درجه & مجذمورع & & \\
\hline 1 & $\cdot / v a$ & $\cdot / \cdots \cdot 1$ & $1 \cdot \mathrm{V} / \mathrm{VA}$ & r৭q/r. & $r$ & Var/a. & مر احل & \\
\hline$\cdot / 9 V$ & . &.$/ \cdot \cdot 1$ & $\mid F / F q$ & Q४६/\। & 1 & ৭४६/V। & كرومبندى & هم آمشتخكى \\
\hline 1 & $\cdot / N r$ & $\cdot / \cdots \cdot \mid$ & $\vee ৭ / Q \Lambda$ & $\begin{array}{l}r \wedge r / \cdot V \\
r / 9 V\end{array}$ & $\begin{array}{l}r \\
\Delta Q\end{array}$ & $\begin{array}{l}\Delta 90 / 10 \\
r \cdot \Delta / 91\end{array}$ & تعامل مراحل و گروهبندى & عمل \\
\hline
\end{tabular}




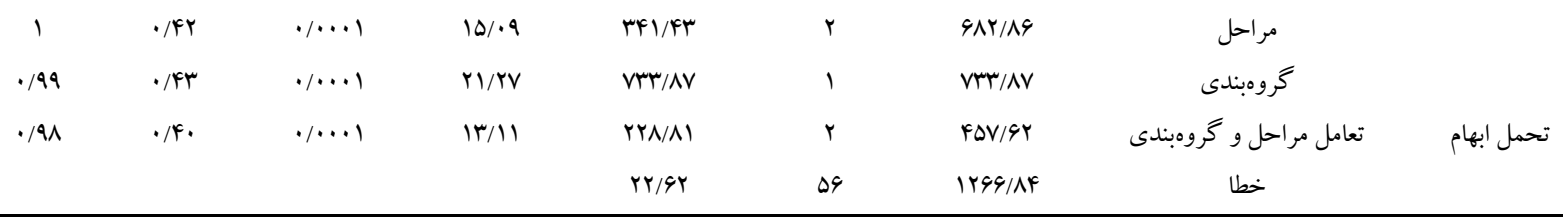

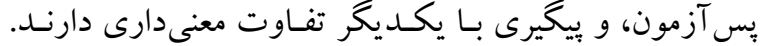

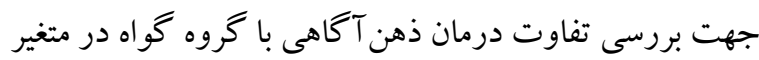

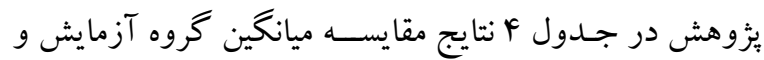

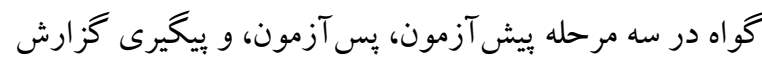

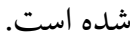

همان كونسه كـه نتايج جدول ب نشــان مىدهد ميز انF اثر

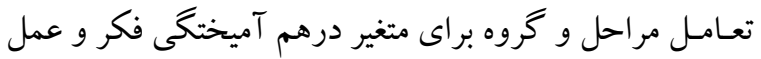

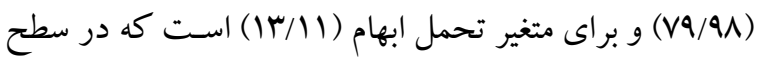

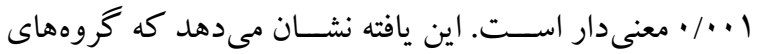

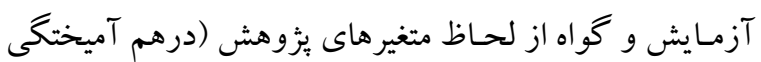

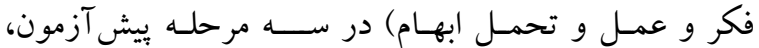

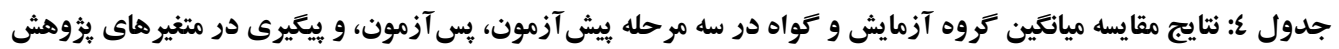

\begin{tabular}{|c|c|c|c|c|c|c|}
\hline سطح معنادارى & خطاى استاندارد & تفاوت ميانكينها & ميانكين & ميانكين آزمايش & مرحله & مؤلفه \\
\hline$\cdot / A V$ & $1 / V^{F}$ & $\cdot / 149$ & $\Delta H / Y q$ & $\Delta r / \Delta r$ & يِيش آزمون & \multirow{4}{*}{ فر آميختكى } \\
\hline$\cdot / \cdots \cdot 1$ & $1 / 19$ & $-\Lambda / 9$ & $\Delta r / A$. & $F \notin / Y$. & پֶ آزمون & \\
\hline$\cdot / \cdots 1$ & 1/AD & $-11 / \Delta r$ & $\Delta r / \cdot G$ & $F \cdot / \Delta r$ & ييخيرى & \\
\hline$\cdot / N 1$ & $1 / A 1$ & $\cdot 194$ & $F 1 / 49$ & Fl/ar & ييش آزمون & \\
\hline$\cdot / \cdots \cdot 1$ & $1 / \Delta F$ & $-\Lambda / \wedge 9$ & $F \mid / A$. & rr/qT & يِ آزمون & \multirow{2}{*}{ تحمل ابهام } \\
\hline$\cdot / \cdots \cdot 1$ & T/Yr & $-\Lambda / 94$ & $r q / 4$. & $r \cdot / 4 q$ & ييخيرى & \\
\hline
\end{tabular}

تحمـل ابهام مبتلايان به اختلال وســـواس بـىاختيارى در مراحل بس آزمون و بيخيرى شود.

\section{بحث و نتيجه تيرى}

يثزوهش حاضر با هدف بررسى اثربخشى درمان ذهن آكاهى بر تحمـل ابهـام و در آميختخى فكر و عمـل مبتلـايـان بـه اختلـال وســواس بىاختيارى انجام گرفت. نتايج حاصـل از تجزيه و تحليل دادهها نشان داد كه درمان ذهن آكًاهى بر تحمل ابهام و

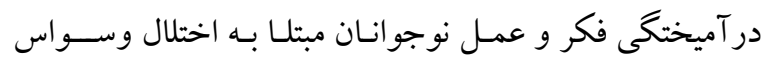

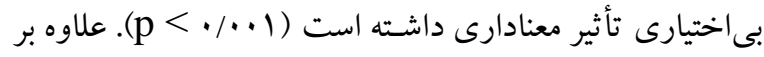
اين نتايج نشان داد كه اين درمان توانسته تأثير خود را در زمان نيز به شكل معنادارى حفظ كند( ( ) نتايج يزوهش حاضسر درباره اثربخشى درمان ذهن آكاهى بر در آميختخى فكر و عمل نوجوانان مبتلا به اختلال وســواس
همـان كونـه نتـايج جدول F نشــان مى دهد، در متغيرهاى در آميختخى فكر و عمل و تحمـل ابهام تفاوت ميانگين كروه آزمـايش بـا كروه گو اه در مرحلـه ييش آزمون (AV/ • و معنى دار نيست و در نتيجه بين دو گرووه آزمايش و كواه در اين مرحله تفاوت معنى دارى وجود ندارد. اما تفاوت ميانگين گرووه

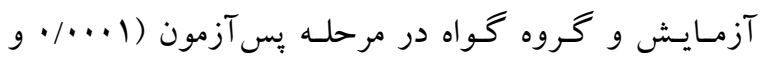

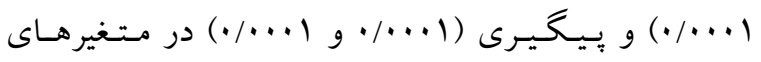
در آميختخى فكر و عمل و تحمـل ابهام، معنى دار اســت، در نتيجـه ميـانگين گروه آزمـايش در اين دو مرحلـه به صسورت معنى دارى متفاوت از ميانخين گُروه گو اهاسـت. اين يافته بدان معنـاسـت كـه درمـان ذهن آخـاهى توانســــه منجر به كاهش در آميختخى فكر و عمل و بهبود در آميختخى فكر و عمل و و 
تمـايلـات اجتنـابى افراد بـا اختلـال وســـواس بـىاختيارى تأثير كذاشته و در نتيجه از اجتناب شناختى و در نتيجه از آميختكى إنى افكار با عمل، جلو گيرى مىشود.

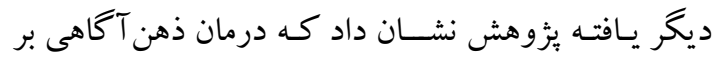
تحمل ابهام نوجوانان مبتلا به اختلال وســواس بى اختيارى تأثير معنادارى داشـته اسـت. همسـو با اين يافته حاضـر، كروسول و

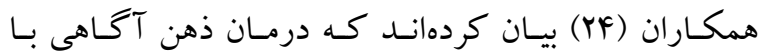
به كار گيرى آكاهى شناختى و هيجانى مى تواند سلامت هيجانى

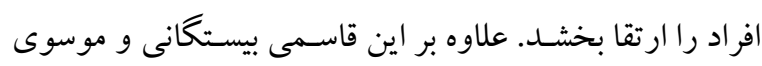

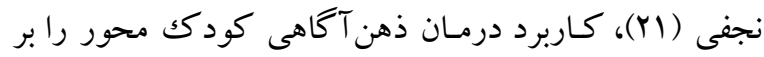
مهارت هاى اجتماعى و خود كار آمدى كود كان مورد بررسـى لهى

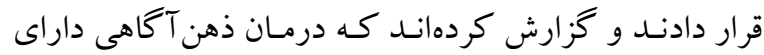

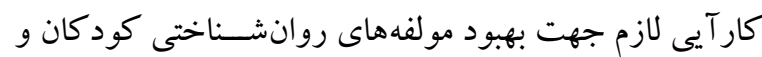
نوجوانـان اســت. در تبيين اين يـافتـه مى توان بيـان كرد كـهـ ذهن آكاهى و مهارتهاى ذهن آكًاهى به افراد يارى مىرسـاند

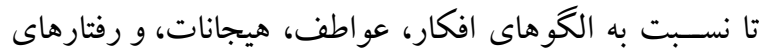
ارتجالى خود بينش و بصـيرت بيدا كند و ســـس بتوانند به

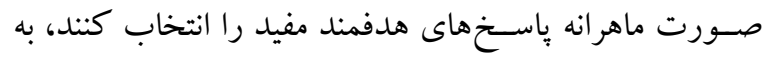
جاى آنكه به طور خودكار با روشهاى خو گرفته و ناهشـيار نسـبت به وقايع محيطى، واكنش نشــان دهند (YD). اين فرايند زمانى مهمم تر جلوه مى كند كه در نظر داشـــه باشـــم نوجوانان

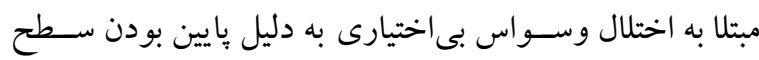

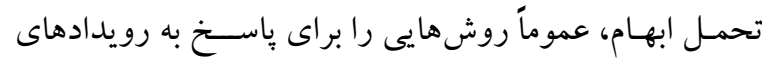

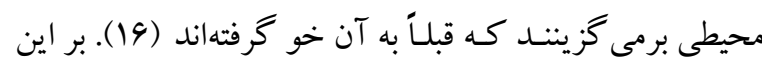

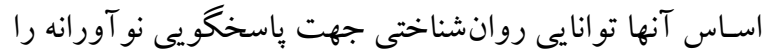
در خود احساس نمى كنند، بنابر اين درمان ذهن آكاهى با ايجاد تغيير در سـاختار عو اطف، احسـاسات، هيجانات، و افكار افراد

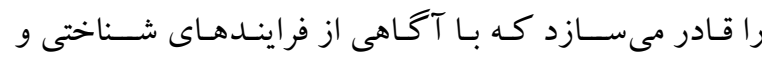

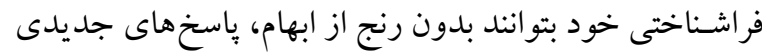
را در فرايند شناختى خود ايجاد و بروز دهند. از محسدوديـتهـاى اين مطـالعهه مى توان بـه وجود برخى متغيرهاى كنترل نشـده، مانند وضـعيت هوشى افراد حاضر در
بى اختيارى همسو با يافته يِى - بريش و همكاران (·r) و هوبِ

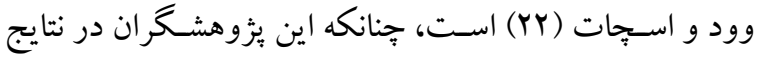

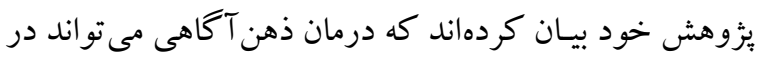
درمـان مؤلفـهــاى روانشــناختى كود كان و نوجو انان داراى آسـيب هاى روانشـناختى، روى آوردى مناسـب به شـمار آيد.

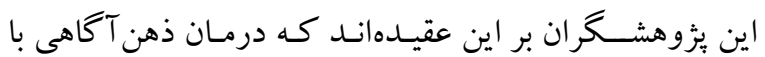

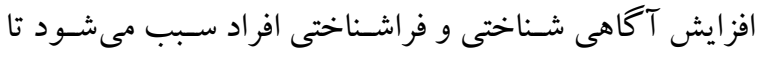

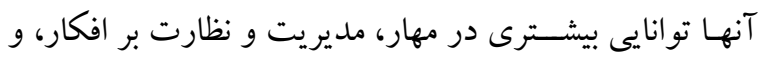

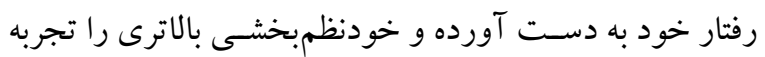

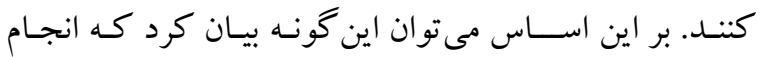

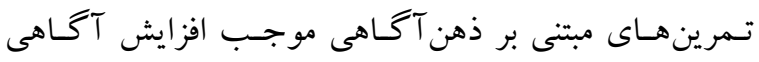

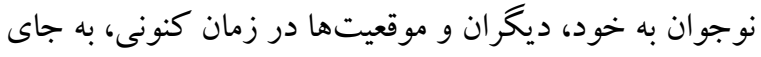
كذشــته و آينده مى شــود. بدين ترتيب افر اد مبتلا به اختلال

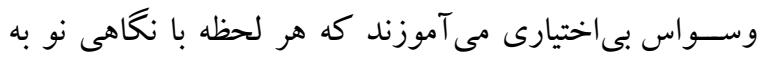
خود و محيط، از طريق بـاســخهـاى ســازشيـافته به جاى واكنشهاى سـريع به موقعيتها، بين خود و زمينه تفاوت قائل

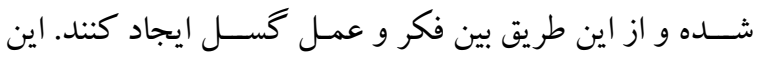

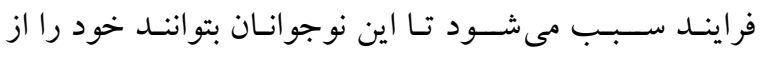

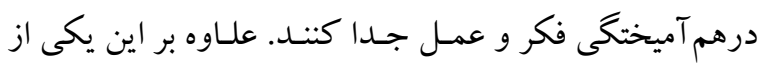

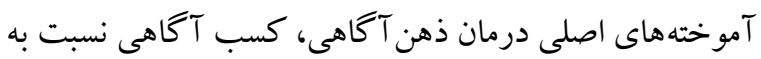
افكـار، احسـاسـات و حس هـاى بدنى بدون قضــاوت و در

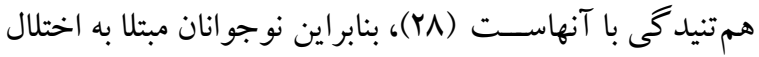

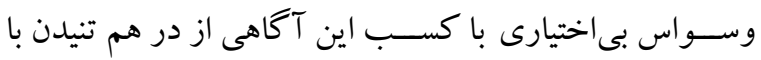

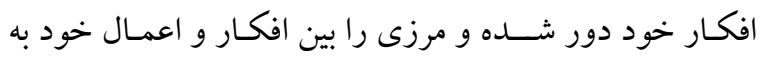

$$
\text { وجود مى آورند. }
$$

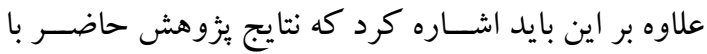

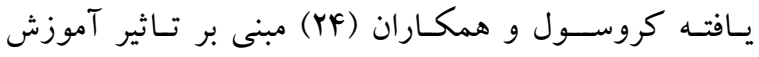

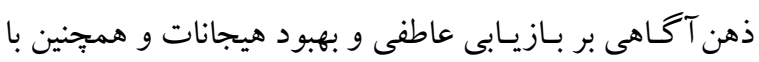

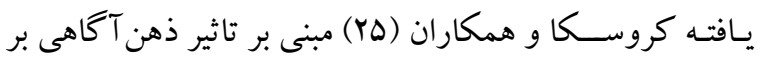
اجتناب شـناختى افراد داراى اختلال وسواس بى اختيارى همسو

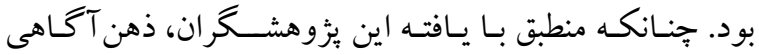
مى توانـد بـا فعال كردن نظام شـــاختى و فراشـــاختى افر اد بر 
مربيـان مدارس آموزش داده شــود تا آنها با به كار گيرى اين

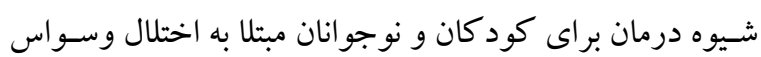

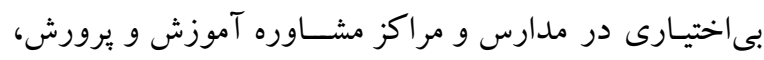

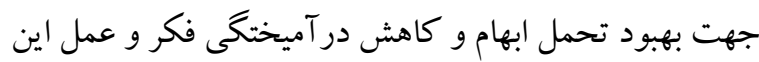
نوجوانان، گامى عملى بر دارند.

تشكر و قدردانى: مقاله حاضر بركرفته از رساله دكتراى تخصصى

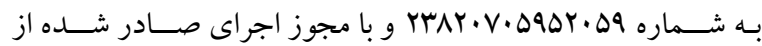

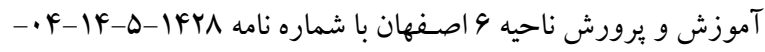

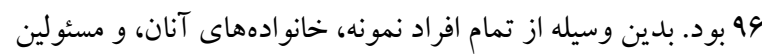

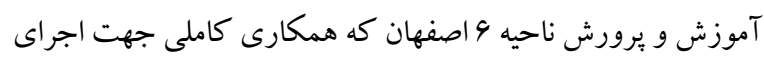
اين بزوهش داشتند، قدردانى به عمل مى آيد.

تضــاد منـافع: در اين يُزوهش هيج گونه تعارض منافعى توسـط

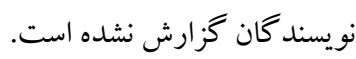

يُزوهش، وضــيت مالى خانو ادهها، تعداد فرزندان و موقعيت اجتمـاعى آنها، و عسدم بهره گيرى از روشهـاى نمونسه گيرى

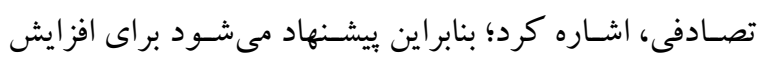
قدرت تعميم بذيرى نتايج، در سـطح بيشــنهاد يثزوهشىى، اين

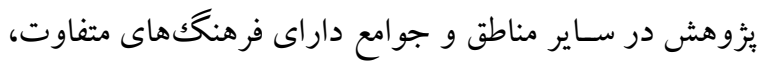

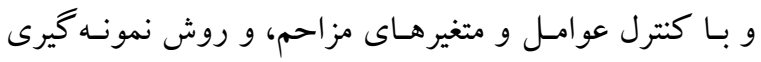

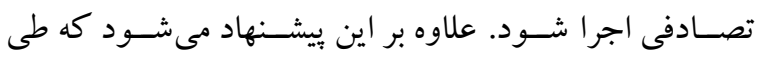

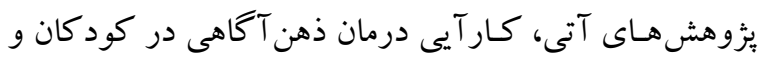

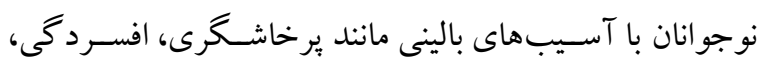

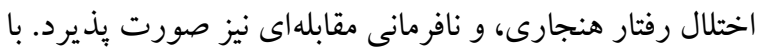

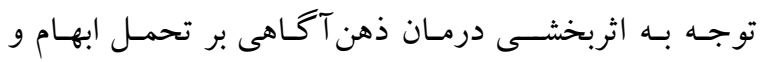
در آميختخى فكر و عمل مبتلايان به اختلال وسو اس بـى اختيارى،

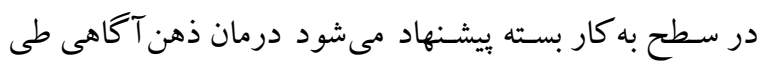
دروههاى آموزشسى ضسمن خدمت تخصسصى به مشـاوران و 


\section{References}

1. Heyman I, Fombonne E, Simmons H, Ford T, Meltzer H, Goodman R. Prevalence of obsessivecompulsive disorder in the British nationwide survey of child mental health. Int Rev Psychiatry. 2003; 15(1-2): 178-184. [Link]

2. Barton B, Heyman I. Obsessive-compulsive disorder in children and adolescents. Paediatr Child Health. 2016; 26(12): 527-533. [Link]

3. Ganji M. Psychological pathology based on DSM-5. Third Edition. Tehran: Savalan; 2018, pp: 322-323. [Persian].

4. Izadi R, Abedi MR. Alleviation of obsessive symptoms in treatment-resistant obsessive-compulsive disorder using acceptance and commitment-based therapy. KAUMS Journal (FEYZ). 2013; 17(3): 275286. [Persian]. [Link]

5. Moreno-Amador B, Piqueras JA, Rodriguez-Jimenez T, Marzo JC, Mataix-Cols D. Adaptation and validation of the dimensional DSM-5 obsessive-compulsive related disorder scales in adolescents: Preliminary data. J Obsessive Compuls Relat Disord. 2018; 19: 99-104. [Link]

6. Reynolds KC, Gradisar M, Alfano CA. Sleep in children and adolescents with obsessive-compulsive disorder. Sleep Med Clin. 2015; 10(2): 133-141. [Link]

7. Rassin E, Diepstraten P, Merckelbach H, Muris P. Thought-action fusion and thought suppression and obsessive -compulsive disorders. Behav Res Ther. 2001; 39(7): 757-764. [Link]

8. Altın M, Gençöz T. How does thought-action fusion relate to responsibility attitudes and thought suppression to aggravate the obsessive-compulsive symptoms? Behav Cogn Psychother. 2011; 39(1): 99-114. [Link]

9. Hezel DM, Stewart SE, Riemann BC, McNally RJ. Clarifying the thought-action fusion bias in obsessivecompulsive disorder. J Obsessive Compuls Relat Disord. 2019; 20: 75-84. [Link]

10. Berle D, Starcevic V. Thought-action fusion: Review of the literature and future directions. Clin Psychol Rev. 2005; 25(3): 263-284. [Link]

11. Shafran R, Rachman S. Thought-action fusion: A review. J Behav Ther Exp Psychiatry. 2004; 35(2): 87-107. [Link]

12. Dugas MJ, Gagnon F, Ladouceur R, Freeston MH. Generalized anxiety disorder: A preliminary test of a conceptual model. Behav Res Ther. 1998; 36(2): 215-226. [Link]

13. Takano K, Tanno Y. Self-rumination, self-reflection, and depression: Self-rumination counteracts the adaptive effect of self-reflection. Behav Res Ther. 2009; 47(3): 260-264. [Link]

14. McLaughlin KA, Nolen-Hoeksema S. Rumination as a transdiagnostic factor in depression and anxiety. Behav Res Ther. 2011; 49(3): 186-193. [Link]

15. Krieger T, Altenstein D, Baettig I, Doerig N, Holtforth MG. Self-Compassion in depression: associations with depressive symptoms, rumination, and avoidance in depressed outpatients. Behav Ther. 2013; 44(3): 501-513. [Link]

16. Faleer HE, Fergus TA, Bailey BE, Wu KD. Examination of an experimental manipulation of intolerance of uncertainty on obsessive-compulsive outcomes. J Obsessive Compuls Relat Disord. 2017; 15: 64-73. [Link]

17. Holaway RM, Heimberg RG, Coles ME. A comparison of intolerance of uncertainty in analogue obsessive-compulsive disorder and generalized anxiety disorder. J Anxiety Disord. 2006; 20(2): 158174. [Link]

18. Krohne HW. Vigilance and cognitive avoidance as concepts in coping research. In: Krohne HW, editor. Attention and avoidance: Strategies in coping with aversiveness. Ashland, OH, US: Hogrefe \& Huber Publishers; 1993, pp: 19-50. [Link]

19. Bordick D. Mindfulness skills for the children and adolescents. Monshe'ie GR, Asli Azad M, Hoseini L, Tayebi P. (Persian translator). First edition. Isfahan: Isfahan Islamic Azad University publication (Khorasgan); 2017, PP: 369-375. [Persian]. 
20. Perry-Parrish C, Copeland-Linder N, Webb L, Sibinga EMS. Mindfulness-based approaches for children and youth. Curr Probl Pediatr Adolesc Health Care. 2016; 46(6): 172-178. [Link]

21. Ghasemi Bistagani M, Musavi Najafi F. Effectiveness of child-centered mindfulness on social skills and self-efficacy of children with learning disabilities. Social Behavior Research \& Health. 2017; 1(2): 91-99. [Link]

22. Hopwood TL, Schutte NS. A meta-analytic investigation of the impact of mindfulness-based interventions on post traumatic stress. Clin Psychol Rev. 2017; 57: 12-20. [Link]

23. Hofmann SG, Gómez AF. Mindfulness-based interventions for anxiety and depression. Psychiatr Clin North Am. 2017; 40(4): 739-749. [Link]

24. Crosswell AD, Moreno PI, Raposa EB, Motivala SJ, Stanton AL, Ganz PA, et al. Effects of mindfulness training on emotional and physiologic recovery from induced negative affect. Psychoneuroendocrinology. 2017; 86: 78-86. [Link]

25. Kroska EB, Miller ML, Roche AI, Kroska SK, O'Hara MW. Effects of traumatic experiences on obsessive-compulsive and internalizing symptoms: The role of avoidance and mindfulness. J Affect Disord. 2018; 225: 326-336. [Link]

26. Semple RJ, Lee J. Chapter 8 - mindfulness-based cognitive therapy for children. In: Baer RA, editor. Mindfulness-based treatment approaches. Second Edition. San Diego: Academic Press; 2014, pp: 161188. [Link]

27. Shapiro SL, Carlson LE, Astin JA, Freedman B. Mechanisms of mindfulness. J Clin Psychol. 2006; 62(3): 373-386. [Link]

30. Armstrong AB. Acceptance and commitment therapy for adolescent obsessive-compulsive disorder [Doctoral Thesis]. [Logan, USA]: Department of Psychology, Utah State University; 2011, pp: 121-124. [Link]

31. Jones PJ, Mair P, Riemann BC, Mugno BL, McNally RJ. A network perspective on comorbid depression in adolescents with obsessive-compulsive disorder. J Anxiety Disord. 2018; 53: 1-8. [Link]

32. Borda T, Neziroglu F, Taboas W, McKay D, Frenkiel L. Overvalued ideation in adolescents with obsessive-compulsive disorder. Psychiatry Res. 2017; 255: 66-71. [Link]

33. Sternberger LG, Burns GL. Maudsley obsessional-compulsive inventory: obsessions and compulsions in a nonclinical sample. Behav Res Ther. 1990; 28(4): 337-340. [Link]

34. Norman RMG, Davies F, Malla AK, Cortese L, Nicholson IR. Relationship of obsessive-compulsive symptomatology to anxiety, depression and schizotypy in a clinical population. Br J Clin Psychol. 1996; 35(4): 553-566. [Link]

35. Mohammadkhani S, Farjad M. The relationship of the metacognitive beliefs and thought control strategies with obsessive-compulsive symptoms in nonclinical population. Journal of Clinical Psychology. 2009; 1(3): 35-51. [Persian]. [Link]

36. Yorulmaz O, Yılmaz AE, Gençöz T. Psychometric properties of the Thought-Action Fusion Scale in a Turkish sample. Behav Res Ther. 2004; 42(10): 1203-1214. [Link]

37. Salmani B, Hasani J. The role of intolerance of uncertainty and positive metacognitive beliefs in obsessive compulsive disorder and depression. Razi Journal of Medical Sciences. 2016; 23(142): 64-72. [Persian]. [Link]

38. Mclain DL. The MSTAT-1: A new measure of individual's tolerance for ambiguity. Educ Psychol Meas. 1993; 53(1): 183-189. [Link] 